\title{
ПРОЕКТИРОВАНИЕ ВЕТРОГЕНЕРАТОРОВ ПОВЫШЕННОЙ МОЩНОСТИ (600 $\div 3600)$ КВТ С ВОЗБУЖДЕНИЕМ ОТ ПОСТОЯННЫХ МАГНИТОВ
}

\author{
Ю.Н. Перминов ${ }^{1}$, канд. техн. наук, Е.А. Монахов ${ }^{2}$, Л.П. Волков ${ }^{3}$ \\ ${ }^{1}$ Институт возобновляемой энергетики НАН Украины, \\ 02094, ул. Гната Хоткевича, 20А, г. Киев, Украина. \\ ${ }^{2}$ Национальный технический университет Украины «Киевский политехнический институт имени Игоря Сикорского», \\ 03056, пр. Победы, 36, г. Киев, Украина. \\ ${ }^{3}$ Институт экологического управления и сбалансированного природопользования, \\ 02002, ул. Никольско-Слободская, 6-Д, г. Киев, Украина.
}

В статье на основе оценки характеристик некоторых ветрозон Украины [1] и применяемой при проектировании скорости ветра за рубежсм проведено сравнение основных параметров ветрогенераторов. Для этого по определенному алгоритму [4-9] был рассчитан ряд синхронных генераторов мощностью от 600 до 3600 кВт с ориентиром на мощности машин, выпускаемых «Заводом крупных электрических машин» (2. Каховка), но за базовую конструкиию при расчетах принят генератор, представленный в [2]. Особенностью конструкции этого генератора - отсутствие ярма статора (корпуса). Корпусом генератора является пакет статора с обмоткой, поэтому он представляет собой модуль головки ветроустановки, это позволяет уменьшить его массу и габариты.

До настоящего времени наиболее широко применились асинхронные генераторы с мультипликаторами для повышения частоты вращения, учитывая, что частота вращения ветроколеса уменьшается с повышением мощности ветроустановки и составляет всего несколько оборотов в минуту. С увеличением частоты вращения уменьшается электромагнитный момент, объем и масса генератора, но увеличиваются соответствующие параметры мультипликатора. В последние годы наметилась тендениия применения безредукторних синхронных генераторов с возбуждением от постоянных магнитов, что позволяет упростить конструкиию агрегата, повысить надежсность установки, исключить необходимость обслужсивания редуктора (мультипликатора) и потери на возбуждение. В связи с этим, в работе проведено сравнение указанных вариантов выполнения агрегатной части ветроустановок по электромагнитным параметрам, массе и габаритам.

Изменение геометрических соотночений генератора определяет его электромагнитные параметры, поэтому отмечены оптимальные отночения диаметров корпуса и ротора, иирины паза и зубй, определена зависимость геометрии зубиовой зонь и мощности от принятого числа пазов на полюс и фазу (q); обоснована возможность применения «меандровой» обмотки в связи с малым расчетным значением числа витков в секиии. Такая обмотка позволяет упростить технологию её изготовления, возможность увеличения коэффищиента заполнения паза и мощности при решении технологических вопросов изготовления. Библ. 9, рис. 3.

Ключевые слова: синхронные генераторы; асинхронные генераторы; мощность ветроустановки; частота вращения; электромагнитный момент; постоянные магниты; числов пазов на полюс и фазу; коэффициент заполнения паза.

\section{DESIGN PERMANENT MAGNET WINDGENERATOR OF INCREASED POWER $(600 \div 3600) \mathrm{KW}$}

\author{
Y. Permynov ${ }^{1}$, candidate of technical sciences, E. Monakhov², L. Volkov ${ }^{3}$ \\ ${ }^{1}$ Institute of Renewable Energy of the National Academy of Sciences of Ukraine, \\ 02094, 20A Hnata Khotkevycha St., Kyiv, Ukraine. \\ ${ }^{2}$ National Technical University of Ukraine «Igor Sikorsky Kyiv Polytechnic Institute», \\ 03056, 37 Peremohy Av., Kyiv, Ukraine. \\ ${ }^{3}$ Institute of ecological management and balanced nature management, \\ 02002, Nikolsko-Slobidska str., 6 D, Kyiv, Ukraine.
}

Based on the assessment of the characteristics of some wind zones in Ukraine [1] and used abroad the wind speed in the design of windgenerators, the paper provides comparison of the main parameters of wind generators. According to a certain algorithm [4-9], a number of synchronous generators with a capacity of 600 to $3600 \mathrm{~kW}$ were calculated with a reference to the power of machines manufactured by the Large Electric Machine Plant (Kakhovka). The design presented in the paper [2] was taken as a basic design, which has not a case. The yoke of the stator plays role of the case. The stator with winding plays role of a module of the head of a wind turbine, that allows to reduce its weight and dimensions.

At the present time asynchronous generators with gears have been most widely used for increasing the speed, because the rotation speed of wind wheel decrease with power increase and is only a few revolutions per minute. With increasing speed, the electromagnetic torque, volume and mass of the generator decrease, but the corresponding parameters of the multiplier increase. In recent years, there has been a tendency to use gearless synchronous generators with permanent magnet excitation, which simplifies the

(C) Ю.Н. Перминов, Е.А. Монахов, Л.П. Волков, 2020

Відновлювана енергетика. 2020. № 1 
design of the unit, improves the reliability of the installation, eliminates the need for maintenance of the gearbox (multiplier) and excitation losses. In this regard, the work compares these options for the implementation of the modular part of wind turbines in terms of electromagnetic parameters, mass and dimensions.

A change in the geometric relationships of the generator determines its electromagnetic parameters, therefore, the optimum ratios of the diameters of the stator and the rotor, the width of the slot and the tooth are determined, the dependence of the geometry of the tooth zone and power on the accepted number of slot per pole and phase $(q)$ is determined; the possibility of using a "meander" winding due to the small calculated value of the number of turns in the section is substantiated. Such a winding allows to simplify the technology of its manufacture, gives the possibility of increasing the fill factor of the slot and power. Ref. 9, fig. 3.

Keywords: synchronous generators; asynchronous generators; wind generator power; rotation speed; electromagnetic torque; permanent magnets; slots per pole and phase; slot filling coefficient.
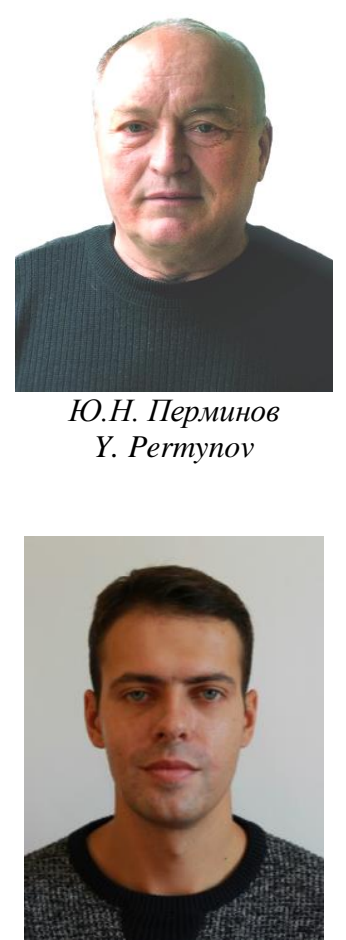

Е.А. Монахов

E. Monakhov

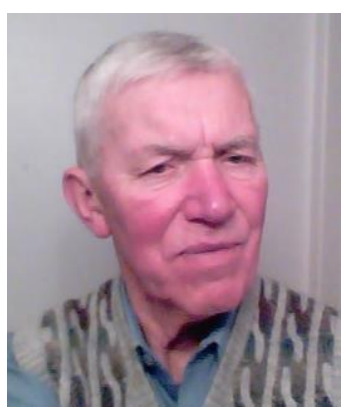

Л.П. Волков

L. Volkov
Сведения об авторе: канд. техн. наук, старший научный сотрудник Института возобновляемой энергетики НАН Украины.

Образование: окончил в 1968 г. Киевский политехнический институт по специальности «Электрические машины и аппараты».

Научная сфера: ветрогенераторы, ветроустановки малой мощности, гидрогенераторы, устройства с постоянными магнитами.

Публікации: 85 .

ORCID: $10000-0001-5604-8327$

Контакты: тел./факс: +38-044-206-28-09

e-mail: renewable@ukr.net

Сведения об авторе: асистент кафедры электромеханики КПИ им. И. Сикорского, Киев. Образование: окончил в 2012 г. Киевский политехнический институт по специальности «Электрические машины и аппараты».

Научная сфера: машины с постоянными магнитами, синхронные генераторы, малые электростанции, гидроэлектростанции.

Публикации: 24.

ORCID: 0000-0001-8408-8051

Контакты: тел./факс: +38-095-317-61-15

e-mail: emonachov@gmail.com

Сведения об авторе: старший научный сотрудник отдела научно-методологического обеспечения Института экологического управления и сбалансированного природопользования, г. Киев.

Образование: окончил в 1959 г. Московский энергетический институт (МЭИ) по специальности «Электрификация промышленных предприятий».

Научная сфера: электропривод, электрические машины.

Публикации: 20.

ORCID: 0000-0003-1988-9666

Контакты: тел./факс: +38-044-206-28-09

e-mail: volleo35@gmail.com
Author information: candidate of technical sciences, Senior Researcher at Institute for Renewable Energy, National Academy of Sciences of Ukraine.

Education: graduated from the Kiev Polytechnic Institute in 1968 with a degree in Electrical Machines and Apparatuses.

Research area: wind power systems, small capacity wind units, hydrogenerators, devices with permanent magnets

Publications: 85.

ORCID: $10000-0001-5604-8327$

Contacts: phone./fax: +38-044-206-28-09

e-mail: renewable@ukr.net

Author information: assistant of department of electomechanics in Igor Sikorsky Kyiv Polytechnic Institute.

Education: graduated from the Kyiv Polytechnic Institute in 2012 with the specialization «Electrical machines and apparatus»».

Research area: permanent magnet machines, synchronous generators, small energy plants, hydropower plants.

Publications: 24

ORCID: 0000-0001-8408-8051

Contacts: phone/fax: +38-095-317-61-15

e-mail: emonachov@gmail.com

Author information: senior staff scientist of scientific-methodological support department in Institute of ecological management and balanced nature management, Kiev.

Education: graduated the Moscow energy institute in 1959 with specialization «Electrification of industrial enterprises»).

Research area: electric drive, electrical machines.

Publications: 20.

ORCID: 0000-0003-1988-9666

Contacts: phone/fax: +38-044-206-28-09

e-mail:volleo35@gmail.com

\section{Перечень используемых обозначений и сокращений:}

$\begin{array}{ll}M_{\text {э }} & - \text { электромагнитный момент; } \\ P & - \text { мощность генератора; } \\ A & - \text { линейная нагрузка; } \\ B_{\delta} & - \text { индукция в рабочем зазоре; } \\ D_{a} & - \text { диаметр ротора; } \\ l_{a} & - \text { активная длина ротора; } \\ \rho & - \text { плотность воздуха; }\end{array}$

\footnotetext{
- скорость воздушного потока;

- к.п.д. ветроколеса;

- диаметр ветроколеса;

- угловая частота вращения;

- коэффициент быстроходности;

- площадь ометаемой поверхности;

- частота напряжения.
} 
Введение. Одним из основных факторов, определяющих мощность ветроустановки, является скорость ветрового потока. В Украине в наиболее активных ветрозонах скорость ветра $(4,5-5)$ м/с [1], поэтому с учётом порывов ветра при проектировании ветрогенераторов для Украины принимается усредненное значение скорости -8 м/с. В зарубежной практике принимается скорость ветра - (12-14) м/с, учитывая применение установок на побережьях (или с выносом в море) и в наиболее активных зонах на материках. Так как мощность ветрового потока определяется кубом скорости, то при таких исходных параметрах при проектировании генераторов их массогабаритные показатели и цена существенно отличаются. До настоящего времени в мощных установках применялись асинхронные генераторы с мультипликаторами для увеличения частоты их вращения, что позволяет при заданной мощности установки пропорционально уменьшить электромагнитный момент и объем ротора при принятых удельных электромагнитных нагрузках (индукции в зазоре и линейной нагрузке). Уменьшение объема ротора сопровождается уменьшением габаритов и массы всего генератора. Однако, при этом растут габариты и масса мультипликатора. Такая взаимосвязь факторов, определяющих массогабаритные показатели всего агрегата, снижение его надёжности и необходимость обслуживания мультипликатора обусловили целесообразность разработки безредукторного синхронного генератора с возбуждением от постоянных магнитов, отличающегося простотой конструкции, отсутствием потерь на возбуждение и надёжностью.

Постановка задачи. В статье рассмотрены некоторые возможные решения задачи создания синхронных ветрогенераторов с возбуждением от постоянных магнитов. Для этого необходимо: учесть усредненное значение скорости ветра при их применении в Украине или за рубежом (табл. 1); оценить целесообразность применения мультипликаторов в агрегате ветроустановки; определить особенности изменение геометрических соотношений зубцовой зоны статора, связанные с малой скоростью вращения генератора в установке без мультипликатора и при этом расмотреть возможные варианты выполнения обмоток; определить оптимальные соотношения основных геометрических размеров - диаметра ротора и статора; учесть особенности проектирования магнитной системы с постоянными магнитами.

Таблица 1. Сравнительные характеристики ветроустановок при разных скоростях ветра (8; 12) м/с.

Table 1. Comparison of windturbine characteristics at different wind speed $(8 ; 12) \mathrm{m} / \mathrm{s}$.

\begin{tabular}{|c|c|c|c|c|c|c|c|c|}
\hline \multirow{2}{*}{$\mathrm{V}, \mathrm{M} / \mathrm{c}$} & & & ГСС-630K & ГСБ-630К & ГСБ-630М & ГСБ800 & СБ-1100 & ГСБ1100L \\
\hline & & & $300 \kappa$ Кт & 630 кВт & 800 кВт & 1000 кВТ & 2750 кВТ & 3600 кВТ \\
\hline \multirow{10}{*}{$8 \mathrm{M} / \mathrm{c}$} & $\mathrm{S}$ & $\left(\mathrm{M}^{2}\right)$ & 3004 & 6309 & 8012 & 10015 & 27541 & 36054 \\
\hline & $\mathrm{D}$ & (M) & 61,8 & 89,6 & 101 & 113 & 187 & 214 \\
\hline & $\omega$ & рад/c & 1,81 & 1,25 & 1,1 & 0,97 & 0,6 & 0,53 \\
\hline & $\mathrm{n}$ & об/мин & 17,2 & 12 & 10,5 & 19 & 6 & 5 \\
\hline & $\mathrm{M}_{3}$ & $H \cdot M$ & 166000 & 506000 & 719000 & 1000000 & 4500000 & 6700000 \\
\hline & $\mathrm{U}$ & $\mathrm{B}$ & 690 & 690 & 690 & 1000 & 1000 & 1000 \\
\hline & $\mathrm{f}$ & $\Gamma ц$ & 50 & 50 & 50 & 50 & 50 & 50 \\
\hline & $\mathrm{D}_{\mathrm{p}}$ & $\mathrm{M}$ & 2,8 & 4 & 4,6 & 5,1 & 8,5 & 9,7 \\
\hline & $l_{p}$ & M & 0,85 & 1,2 & 1,38 & 1,53 & 2,55 & 2,9 \\
\hline & Dк & M & 3,22 & 4,6 & 5,29 & 5,86 & 9,77 & 11,15 \\
\hline \multirow{10}{*}{$12 \mathrm{~m} / \mathrm{c}$} & $\mathrm{S}$ & $\left(\mathrm{M}^{2}\right)$ & 347 & 729 & 926 & 1157 & 1591 & 4166 \\
\hline & $\mathrm{D}$ & (м) & 21 & 30 & 34 & 38 & 45 & 73 \\
\hline & $\omega$ & рад/c & 8 & 5,6 & 5 & 4,5 & 3,8 & 2,3 \\
\hline & $\mathrm{n}$ & об/мин & 76 & 53,5 & 48 & 43 & 36 & 22 \\
\hline & $\mathrm{M}_{3}$ & $H \cdot M$ & 37500 & 112500 & 160000 & 222000 & 723000 & 1565000 \\
\hline & $\mathrm{U}$ & $\mathrm{B}$ & 690 & 690 & 690 & 1000 & 1000 & 1000 \\
\hline & $\mathrm{f}$ & $\Gamma ц$ & 50 & 50 & 50 & 50 & 50 & 50 \\
\hline & $D_{p}$ & M & 1,7 & 2,5 & 2,8 & 3,1 & 4,6 & 5,9 \\
\hline & $l_{p}$ & $M$ & 0,51 & 0,75 & 0,84 & 0,93 & 1,38 & 1,77 \\
\hline & $\mathrm{D}_{\mathrm{K}}$ & M & 1,95 & 2,87 & 3,22 & 3,56 & 5,29 & 6,78 \\
\hline
\end{tabular}


В табл. 1 приняты следующие обозначения: $\mathrm{S}$ - площадь ометаемой поверхности ветроколеса $\left(\mathrm{M}^{2}\right), \mathrm{D}$ - диаметр ветроколеса (м), $\omega$ - угловая частота вращения ветроколеса (рад/c), n - скорость вращения ветроколеса (об/мин), $\mathrm{M}_{3}$ - электромагнитный момент генератора $(\mathrm{H} \cdot \mathrm{M}), \mathrm{U}-$ напряжение генератора (B), f - частота напряжения (Гц), $\mathrm{D}_{\mathrm{p}}$ - диаметр ротора генератора (м), $\mathrm{L}_{\mathrm{p}}-$ активная длина ротора генератора (м), $\mathrm{D}_{\kappa}$ - диаметр корпуса генератора (м).

Одним из основных факторов, определяющих массогабаритные показатели, а также стоимость цену ветроустановки является скорость ветрового потока. В Украине составлены карты ветрозон [1], позволяющие определить усредненные скорости ветрового потока в различных регионах. Установлено, что наибольшие скорости ветра наблюдаються в Херсонской области, Крыму, Карпатах, где скорость ветра изменяется от 4,5 до 5 м/с, а порывы ветра - до 8 м/с и более, которые составляет примерно $20 \%$ общего времени работы установки. Поэтому при проектировании генераторов применительно к Украине принимается расчётная скорость ветра около 8 м/с. В зарубежной практике предполагается, что скорость ветра составляет - 12-14 м/с, учитывая их использование в наиболее активных зонах материков, на побережьях морей и океанов и выноса их в море. Принятые скорости ветра обуславливает существенную разницу расчётных параметров установок.

Мощность ветрового потока определяется зависимостью:

$$
P=\frac{\rho \cdot S \cdot v^{3} \cdot k}{2 \cdot \eta}
$$

где $v$ - скорость ветрового потока (м/с); $\rho=1,3$ $\kappa 2 / \mathcal{M}^{3}$ - плотность воздуха; $S$ - площадь ометаемой поверхности ветроколеса $\left(\mathrm{M}^{2}\right)$; $k \approx 0,38 \div 0,4$ - коэффициент использования ветрового потока; $\eta$ - к.п.д. генератора.

Из (1) определяются площадь ометаемой поверхности

$$
S=\frac{2 \cdot P}{\rho \cdot v^{3} \cdot k},
$$

диаметр ветроколеса

$$
D=\sqrt{\frac{S}{0,785}},(\text { м) }
$$

угловая частота вращения ветроколеса

$$
\varpi=\frac{z^{\prime} \cdot v}{R}, p a d / c,
$$

где $z^{\prime} \approx(4,5-6)$ - коэффициент быстроходности осевого ветроколеса, представляющий отношение линейной скорости вращения концов лопастей колеса к скорости набегающего потока, а $R$ - радиус ветроколеса (м).

По угловой частоте вращения (4) и заданной частоте выходного напряжения $(f)$ определяются число пар полюсов магнитной системы генератора

$$
p=\frac{f \cdot 60}{n}
$$

и электромагнитный момент генератора

$$
M_{\ni}=\frac{P}{\varpi} .
$$

Из формулы для электромагнитного момента

$$
M_{\ni}=\alpha_{i} \cdot A_{c p} \cdot B_{\delta c p} \cdot \pi \cdot D_{p}^{3} \cdot \lambda,(\mathrm{H} \cdot \mathrm{M})
$$

определяется диаметр ротора

$$
D_{p}=\sqrt[3]{\frac{M_{\ni}}{\alpha_{i} \cdot A_{c p} \cdot B_{\delta c p} \cdot \pi \cdot \lambda}},(\mathrm{M}),
$$

где: $\alpha_{i}$ - коэффициент полюсного перекрытия; $A_{c p} \approx 13 \cdot 10^{3}(\mathrm{~A} / \mathrm{M}) \quad-$ линейная нагрузка; $B_{\delta c p} \approx 0,78$ (Тл) - средняя величина индукции в рабочем зазоре; $\lambda=\frac{L_{p}}{D_{p}}-$ отношение активной длины ротора к диаметру;

Величины удельных электромагнитных нагрузок $\left(A_{c p}, B_{\delta c p}\right)$ приняты на основе опыта проектирования и результатов испытаний машин с возбуждением от постоянных магнитов [2]. По проведённому алгоритму (1)-(7) был рассчитан ряд генераторов без мультипликаторов мощностью от 300 до 3600 кВт с ориентиром на мощно- 
сти электрических машин, выпускаемых «Заводом крупных электрических машин» (г. Каховка), но за базовую конструкцию при расчётах принят генератор, представленный в [2]. Особенность конструкции этого генератора - отсутствие ярма статора (корпуса). Корпусом генератора является пакет статора с обмоткой, поэтому он представляет собой модуль головки ветроустановки, корпус которой является корпусом генератора, что позволяет уменьшить его массу и габариты. Ротор генератора представляет собой многополосную радиальную магнитную систему с магнитами NdFeB, отличающихся высоким уровнем магнитных параметров: остаточная индукция $\mathrm{B}_{\mathrm{r}}=(0.93-1.1)$ Тл, коэрцитивная сила $-\mathrm{H}_{\mathrm{c}}=(930-$ 1100) кА/м, что позволяет минимизировать массогабаритные показатели генератора. Статор генератора - пазовый с всыпной двухслойной обмоткой, но как будет показано ниже, могут быть и другие варианты обмоток. Для улучшения агрегатирования генератора в головку ветроустановки он выполнен уплощённой конструкции, с малым отношением активной длины ротора к его диаметру.

Приведенные в табл.1 результаты расчётов основных геометрических размеров ветроколес и генераторов мощностью (300-3600) кВт на разных скоростях ветра $(8 ; 12)$ м/с показывают существенно завышенную массу и габариты генераторов и ветроколес на меньшей скорости ветрового потока. Поэтому для повышения эффективности ветроустановок целесообразно увеличивать высоту опор для использования потоков воздуха с большей скоростью, однако, при этом растёт стоимость и усложняется монтаж установки. Эффективность ветроустановки может быть также повышена за счет агрегатной части в целом и генератора в частности.

До настоящего времени наиболее широко применялись асинхронные генераторы с мультипликаторами для повышения частоты вращения, учитывая, что частота вращения ветроколеса уменьшается с повышением мощности установки и составляет всего несколько оборотов в минуту (табл.1), а электродвижущая сила генератор про- порциональна частоте его вращения. С увеличением частоты вращения уменьшается электромагнитный момент (6) и объем генератора, однако при этом увеличиваются объем и масса, усложняется конструкция мультипликатора и растут габариты всей агрегатной части установки. Поэтому в последние годы стали применяться синхронные генераторы мегаваттной мощности (6 MBT, GE, Haliade offshore wind turbine; 7 MBT MSPMG) с возбуждением от постоянных магнитов типа $\mathrm{NdFeB}$ без мультипликаторов. Такие генераторы отличаются простотой конструкции, отсутствием потерь на возбуждение, надёжностью, что позволяет их использование в суровых климатических условиях. Примером может служить ветроустановка NW 100/19, разработанная фирмой Northern при участии NASA, научного фонда (NSF), министерства энергетики (NREL) и компании Siemens-Westinghouse. Модель NW 100/19 специально разработана для работы в экстремальных условиях (Аляска) имеет характеристики, которые облегчают её использование для работы в автономных и изолированных от централизованной электрической сети системах. Она отличается от традиционных ВЭУ отсутствием трансмиссии, постоянным шагам лопастей, минимальным количеством движущихся и чувствительных к внешним воздействиям частей, простотой конструкции ротора, который представляет собой «колесо со спицами», на обечайки которого размещены постоянные магниты как составляющие части радиальной магнитной системы.

Общие характеристики асинхронных генераторов с мультипликаторами и синхронных безредукторных генераторов с возбуждением от постоянных магнитов могут быть более полно представлены в табл. 2. В табл. 2 приведены сравнительные параметры двух ветроустановок одинаковой мощности - 600 кВт с асинхронным генератором и мультипликатором - серийно выпускавшейся установки «TURBOWINDS T60048» и расчетные значения параметров синхронного генератора без мультипликатора с возбуждением от постоянных магнитов $\mathrm{NdFeB}$, конструкция которого описано ранее [2]. 
Таблица 2. Сравнительные характеристики асинхронного генератора с трансмиссией и синхронного генератора с возбуждением от постоянных магнитах при равных мощностях и скорости ветра 12 м/с.

Table 2. Comparative characteristics of asynchronous gearbox generator and permanent magnet synchronous gearless generator with equal power.

\begin{tabular}{|c|c|c|c|c|c|c|c|c|c|c|c|c|}
\hline Тип генератора & $\mathrm{N}$ & $\begin{array}{c}\mathrm{D}_{\mathrm{K}}, \\
\mathrm{M}\end{array}$ & $\mathrm{k}_{\tilde{\sigma}}$ & $\begin{array}{c}\mathrm{n}_{\mathrm{K}}, \\
\text { об/мин }\end{array}$ & $\begin{array}{l}\mathrm{P}_{\mathrm{H}}, \\
\kappa \mathrm{KT}^{-}\end{array}$ & $\begin{array}{c}\mathrm{n}_{\mathrm{H}}, \\
\text { об/мин }\end{array}$ & $\begin{array}{l}\mathrm{M}_{\mathrm{H}}, \\
\mathrm{H} \cdot \mathrm{M}\end{array}$ & $\begin{array}{c}\mathrm{U}_{\mathrm{H}}, \\
\mathrm{B}\end{array}$ & $\mathrm{I}_{\phi н}, \mathrm{~A}$ & $\eta$ & $\begin{array}{c}\mathrm{D}_{\mathrm{p}}, \\
\mathrm{M}\end{array}$ & $\begin{array}{l}1_{p}, \\
M\end{array}$ \\
\hline \multirow{3}{*}{$\begin{array}{c}\text { Асинхронный } \\
\text { (с трансмиссией) }\end{array}$} & 3 & 48 & 4,6 & 24 & 600 & 1500 & 4000 & 690 & 326 & 0,9 & 0,64 & 0,74 \\
\hline & $\begin{array}{c}\mathrm{D}_{\mathrm{M}}, \\
\mathrm{M}\end{array}$ & $\begin{array}{c}1_{\mathrm{M}}, \\
\mathrm{M}\end{array}$ & $\begin{array}{c}\mathrm{m}_{\mathrm{r}}, \\
\mathrm{T}\end{array}$ & $\begin{array}{c}\mathrm{m}_{\mathrm{M}}, \\
\mathrm{T}\end{array}$ & $\underset{\mathrm{T}}{\sum \mathrm{m},}$ & $\begin{array}{c}\mathrm{A}, \\
\mathrm{A} / \mathrm{M}\end{array}$ & $\begin{array}{l}\mathrm{B}_{\delta}, \\
\text { Тл }\end{array}$ & $\cos \varphi$ & $\begin{array}{c}\text { Руд, } \\
\kappa В \mathrm{~T} / \mathrm{M}^{2}\end{array}$ & $\begin{array}{l}\text { lo, } \\
\text { M }\end{array}$ & $\begin{array}{c}\mathrm{D}_{\mathrm{кг}}, \\
\mathrm{M}\end{array}$ & $\begin{array}{c}1_{\text {кт, }} \\
\mathrm{M}\end{array}$ \\
\hline & 1,45 & 1,63 & 3 & 5,4 & 8,4 & 8200 & 0,8 & 0,89 & 5,3 & 3 & 0,9 & 1,4 \\
\hline Тип генератора & $\mathrm{N}$ & $\begin{array}{c}\mathrm{D}_{\mathrm{K}}, \\
\mathrm{M}\end{array}$ & $\mathrm{k}_{\sigma}$ & $\begin{array}{c}\mathrm{n}_{\mathrm{\kappa}}, \\
\text { об/мин }\end{array}$ & $\begin{array}{l}\mathrm{P}_{\mathrm{H}}, \\
\mathrm{KBT}\end{array}$ & $\begin{array}{c}\mathrm{n}_{\mathrm{H}}, \\
\text { об/мин }\end{array}$ & $\begin{array}{l}\mathrm{M}_{\mathrm{H}}, \\
\mathrm{H} \cdot \mathrm{M}\end{array}$ & $\begin{array}{c}\mathrm{U}_{\mathrm{H}}, \\
\mathrm{B}\end{array}$ & $\mathrm{I}_{\phi \mathrm{н}}, \mathrm{A}$ & $\eta$ & $\begin{array}{c}D_{p}, \\
M\end{array}$ & $\begin{array}{l}\mathrm{l}_{\mathrm{p}}, \\
\mathrm{M}\end{array}$ \\
\hline \multirow{3}{*}{$\begin{array}{c}\text { Синхронный } \\
\text { (без трансмиссии) }\end{array}$} & 3 & 46 & 4,6 & 24 & 600 & 24 & 238 & 690 & 309 & 0,96 & 3,4 & 0,2 \\
\hline & $\begin{array}{c}\mathrm{D}_{\mathrm{M}}, \\
\mathrm{M}\end{array}$ & $\begin{array}{c}1_{\mathrm{M}}, \\
\mathrm{M}\end{array}$ & $\begin{array}{c}\mathrm{m}_{\mathrm{r}}, \\
\mathrm{T}\end{array}$ & $\begin{array}{c}\mathrm{m}_{\mathrm{M}}, \\
\mathrm{T}\end{array}$ & $\underset{\mathrm{T}}{\sum \mathrm{m},}$ & $\begin{array}{c}\mathrm{A}, \\
\mathrm{A} / \mathrm{M}\end{array}$ & $\begin{array}{l}\mathrm{B}_{\delta}, \\
\text { Тл }\end{array}$ & $\cos \varphi$ & $\begin{array}{c}\mathrm{P}_{\text {уд, }} \\
\kappa \mathrm{\kappa T} / \mathrm{M}^{2} \\
\end{array}$ & $\begin{array}{l}10, \\
\mathrm{M}\end{array}$ & $\begin{array}{c}\mathrm{D}_{\mathrm{Kг}}, \\
\mathrm{M}\end{array}$ & $\begin{array}{c}1_{\mathrm{KT}}, \\
\mathrm{M} \\
\end{array}$ \\
\hline & - & - & 8 & - & 8 & 10 & 0,8 & 0,94 & 5,5 & 0,3 & 3,5 & 0,3 \\
\hline
\end{tabular}

В табл. 2 приняты следующие обозначения: $\mathrm{N}$ - количество лопастей ветроколеса, $\mathrm{D}_{\text {к }}$ диаметр ветроколеса, $\mathrm{k}_{\sigma}$ - коэффициент быстроходности ветроколеса, $\mathrm{n}_{\mathrm{K}}$ - частота вращения ветроколеса, $\eta_{\kappa}-$ к.п.д. ветроколеса, $\mathrm{P}_{\text {н }}-$ номинальная мощность ветроустановки, $\mathrm{n}_{\text {н }}$ - частота вращения генератора, $\mathrm{M}_{\mathrm{H}}$ - номинальный момент генерато$\mathrm{pa}, \mathrm{U}_{\mathrm{н}}-$ номинальное фазное напряжение, $\mathrm{I}_{\phi н}-$ номинальный фазный ток, $\eta$ - к.п.д. генератора, $D_{p}$ - диаметр ротора генератора, $l_{p}$ - активная длина ротора генератора, $\mathrm{D}_{\mathrm{M}}$ - диаметр корпуса мультипликатора, $1_{\mathrm{M}}$ - длина корпуса мультипликатора, $\mathrm{m}_{\text {г }},-$ масса генератора, $\mathrm{m}_{\mathrm{M}}$ - масса мультипликатора, $\sum \mathrm{m}$ - общая масса агрегата, A - линейная нагрузка, $\mathrm{B}_{\delta}-$ индукция в рабочем зазоре, $\cos \varphi$ - коэффициент мощности, $\mathrm{P}_{\text {уд }}$ - удельные потери с поверхности корпуса без торцов, $1_{0}$ общая длина агрегата, $\mathrm{D}_{\text {кг }}$ - диаметр корпуса генератора, $1_{\text {кг }}$ длина корпуса генератора.

Как видно из табл. 2, при равных скоростях ветра, одинаковых мощности установок, геометрических размерах и конструкциях ветроколес і сравнимых удельных электромагнитных нагрузках генераторов $\left(\mathrm{B}_{\delta}, \mathrm{A}\right)$, асинхронный генератор с мультипликатором и синхронный генератор без мультипликатора (безкорпусной) имеют сравнимые массы, но при этом существенно отличаются габаритами: асинхронный генератор с мультипликатором имеет суммарный осевой размер - 3 м при диаметрах корпуса генератора Dкг $\approx 0,9$ м и корпуса мультипликатора - Dм $\approx 1,45$ м; синхронный генератор (безкорпусной, с возбуждением от постоянных магнитов) имеет диаметр корпуса Dкг $\approx 3,5$, осевой размер 1кг $\approx 0,3 \mathrm{M}$. При этом, учитывая указанные преимущества такой конструк- ции, можно считать её более перспективный и необходимо решать вопросы оптимального проектирования для повышения эффективности синхронного генератора со возбуждением от постоянных магнитов. Для этого был проведён расчёт ряда генераторов мощностью от 20 кВт до 2000 кВт.

Такой подход позволяет установить геометрические соотношений генераторов близкие к оптимальным с учётом требуемых номинальных параметров (напряжения и его частоты, частоты вращения ветроколеса, коэффициента полезного действия, габаритов генератора) без различных допущений с учётом насыщения участка магнитной цепи, допустимых электромагнитных нагрузок (удельного теплового потока, плотности тока, температуры), требований агрегатирования генератора в головку ветроустановки и возможных технологических ограничений при изготовлении генератора.

Одно из основных требований к электрическим генераторам - высокий удельный момент и мощность, определяемых отношением этих параметров к объему (массе) устройства. Так при заданном диаметре корпуса генератора (пакета статора) увеличение диаметра ротора происходит увеличение полного магнитного потока $\left(\mathrm{p} \Phi_{\delta}\right)$ и уменьшения полного тока $(\mathrm{j}(\mathrm{Nq}))$, где $\mathrm{j}$ - допустимая по опыту проектирования плотность тока в обмотке, $\mathrm{Nq}$ - полное сечение токового слоя, определяемое числом проводников $(\mathrm{N})$ и сечением проводника. Электромагнитный момент (исходя из технического задания - скорости ветра и мощности ветроустановки) генератора, определяется произведением полного магнитного потока на полной ток (7). При этом необходимо, чтобы 
индукция в спинках статора и ротора не превышала значений выше колена кривой намагничивания применяемой марки стали. Подобные закономерности наблюдаются и непосредственно в зоне зубец - паз. Ограничением полезного потока зубцовых машинах с радиальной магнитной системой является насыщение зубцов, поэтому расширение зубцов сопровождается увеличением полезного потока, но при определённом зубцо- вом делении (зубец и паз) происходит сужение паза, то есть уменьшается сечения проводников (Nq) и полного тока. В результате должно быть выдержано оптимальное соотношение ширины зубца и паза. В табл. 3 приведены результаты расчётов указанного ряда генераторов, позволяющие определить приемлемые геометрические соотношения генераторов рассматриваемой конструкции при их проектировании.

Таблица 3. Изменение геометрических соотношений генераторов мощностью (20-2000) кВТ.

Table 3. The change of the geometry relationships with powers of (20-2000) $\mathrm{kW}$.

\begin{tabular}{|c|c|c|c|c|c|c|c|c|c|c|c|c|c|c|c|}
\hline $\mathrm{P}$ & $\mathrm{n}$ & $\mathrm{U}_{\phi}$ & $\mathrm{f}$ & $\mathrm{D}_{\text {к }}$ & $\mathrm{D}_{\mathrm{p}}$ & $\mathrm{b}_{\mathrm{z}}$ & $\mathrm{b}_{\text {п }}$ & $\mathrm{b}_{\mathrm{z}} / \mathrm{b}_{\text {п }}$ & $\mathrm{h}_{\text {п }}$ & $\mathrm{h}_{\text {л }}$ & $\delta$ & $\lambda$ & $\mathrm{D}_{\text {к }} / \mathrm{D}_{\mathrm{p}}$ & $\mathrm{P}_{\text {уд }}$ & $\theta$ \\
\hline кВт & об/мин & $\mathrm{B}$ & Гц & мм & мм & мм & мм & о.е. & мм & мм & мм & о.е. & о.е. & Вт/м & град. \\
\hline 20 & 100 & 220 & 30 & 819 & 700 & 12 & 10 & 1,2 & 20 & 20 & 1,5 & 0,3 & 1,08 & 3000 & 45 \\
\hline 50 & 50 & 220 & 50 & 1271 & 1180 & 6 & 5 & 1,2 & 28 & 15 & 2,5 & 0,3 & 1,077 & 4200 & 65 \\
\hline 120 & 32 & 220 & 50 & 1849 & 1723 & 6,5 & 6 & 1,06 & 45 & 17 & 3 & 0,3 & 1,073 & 5500 & 80 \\
\hline 600 & 14 & 690 & 50 & 3431 & 3251 & 4,24 & 4 & 1,06 & 56 & 20,5 & 4 & 0,3 & 1,055 & 5600 & 81 \\
\hline 2000 & 8 & 690 & 50 & 4642 & 4420 & 6,3 & 6 & 1,05 & 75 & 30 & 6 & 0,3 & 1,05 & 5650 & 82 \\
\hline
\end{tabular}

В таблице 3 приняты следующие обозначения: $\mathrm{n}$ - частота вращения ветроколеса (генератора), $\mathrm{U}_{\phi}$ - фазное напряжение, $\mathrm{f}$ - частота выходного напряжения, $\mathrm{D}_{\mathrm{\kappa}}$ - диаметр корпуса генератора, который в рассматриваемой конструкции равен диаметру пакета статора, $\mathrm{D}_{\mathrm{p}}$ - диаметр ротора генератора, $b_{z}$ - ширина зубца, $b_{п}-$ ширина паза, $b_{z} / b_{\text {п }}-$ относительное значения ширины зубца и ширины паза, $\mathrm{h}_{\text {п }}$ - глубина паза, $\mathrm{h}_{\text {я }}$ - толщина пакета статора, $\delta$ - полный немагнитный зазор, $\lambda$ - отношение активной длины ротора к его диаметру, $\mathrm{D}_{\mathrm{K}} / \mathrm{D}_{\mathrm{p}}$ - относительные значения диаметров корпусов статора и ротора, $\mathrm{P}_{\text {уд }}-$ удельные потери с внешней поверхности статора, $\theta$ - превышение температуры статора над температурой окружающей среды.

Как видно из табл. 3, генераторы повышенной мощности имеют небольшие ширину паза и зубца $\left(\mathrm{b}_{z}\right.$ и $\left.\mathrm{b}_{\text {п }}\right)$ при большой глубине паза $\left(\mathrm{h}_{\pi}\right)$. Данное обстоятельство объясняется прежде всего низкой частотой вращения безредукторных вет- рогенераторов (табл.1). Поэтому при заданной частоте напряжения (f) и определённой частоте вращения ветроколеса необходимо большое число полюсов магнитной системы (5), что обуславливает малую величину зубцового деления, а следовательно, малые величины ширины зубца и паза. Сравнительно большая глубина паза определяется при этом большими токами, требуемым полным сечением токового слоя $(\mathrm{Nq})$ с увеличением мощности генераторов. Такая геометрия зубцовой зоны может сопровождаться технологическими трудностями изготовления пакета статора и обмотки, поэтому были проведены расчёты генератора мощностью 600 кВт с разным значением числа пазов на полюс и фазу (q=0,3;0,5;1). Уменьшение "q" сопровождается увеличением зубцового деления, ширины зубца и паза (рис. 1а - q=1, рис. $16-q=0.5)$, но при этом несколько уменьшается мощность генератора (рис. 2), так как изменяется коэффициент распределения обмотки [3]. 


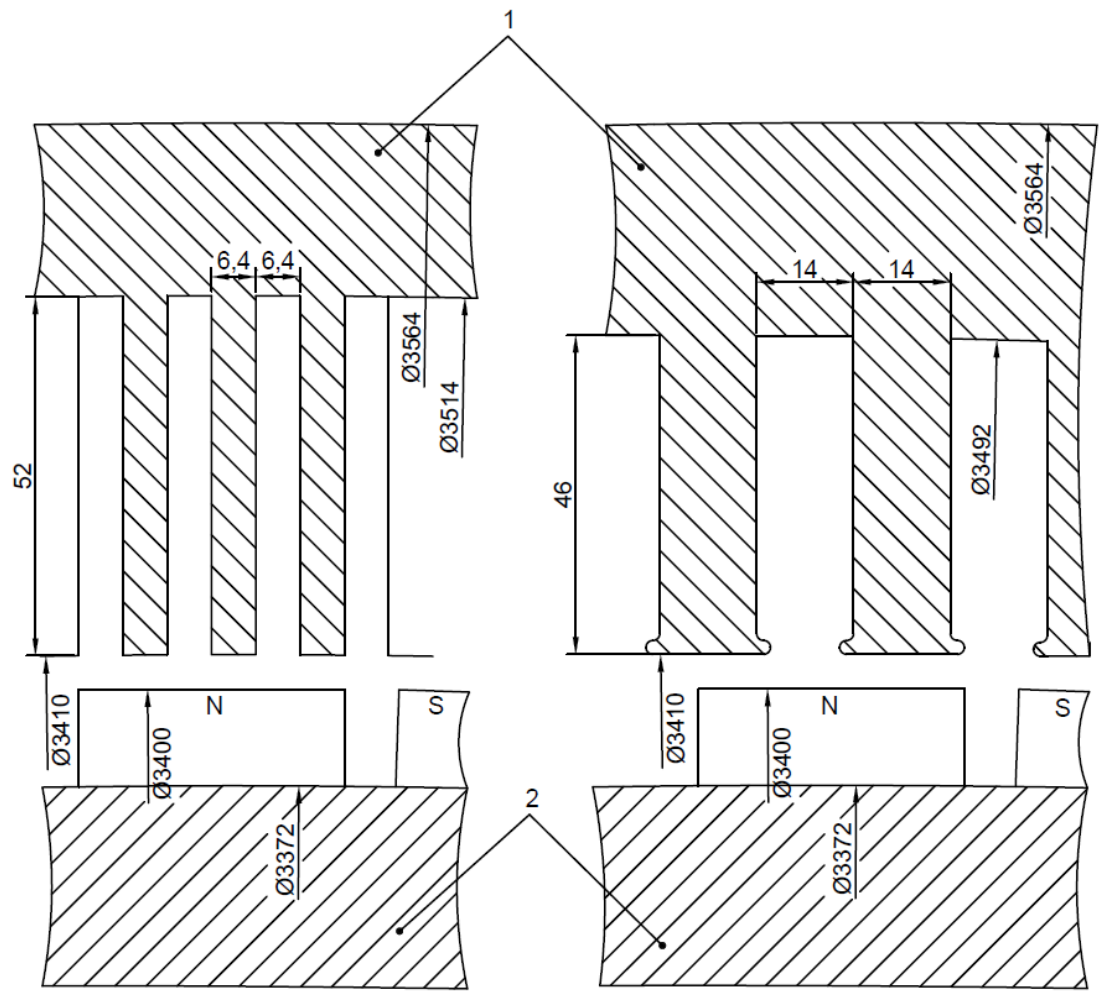

a)

б)

Рис. 1. Фрагмент магнитной системы генератора мощностью 600 кВт: 1 - пакет статора; 2 - ярмо ротора.

Fig. 1. Fragment of magnetic system of $600 \mathrm{~kW}$ generator: 1 - stator core, 2 - rotor yoke.

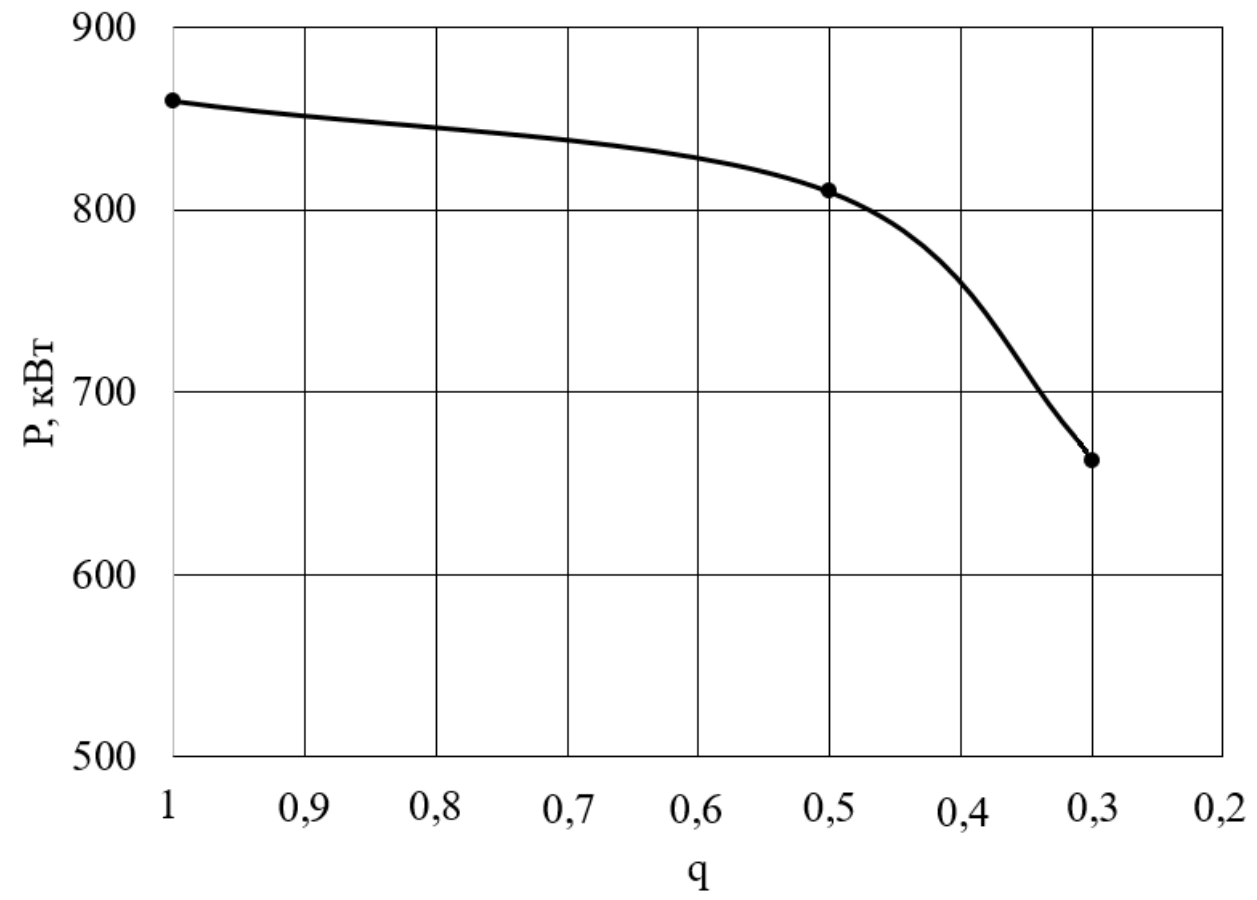

Рис. 2. Зависимость мощности генератора от числа пазов на полюс и фазу (q).

Fig. 2. Power dependence on the quantity of slots per pole and phase (q). 
Для упрощения изготовления обмотки при больших токах и сечении проводников и малой ширине паза может применяться, как вариант, всыпная двухслойная обмотка из нескольких параллельных ветвей в фазе и параллельных проводников в секции для уменьшения сечения элементарного проводника. Как показали расчёты машин при определении числа витков секции по известной формуле [3]

$$
E=4,44 \cdot f \cdot W_{\phi} \cdot \Phi \cdot k_{\text {об }}
$$

число витков в секции $-\mathrm{W}_{\mathrm{c}}=0,5$ с большим требуемым сечением фазного провода с одним проводником в пазу обусловит возможность выполнения трехфазной обмотки в виде трёх независимых меандров, разнесённых по высоте глубокого паза в трёх плоскостях (рис. 3) для исключения пересечения меандров большого сечения в лобовых частях обмотки и сдвинутых на $120^{\circ}$ электрических градусов.

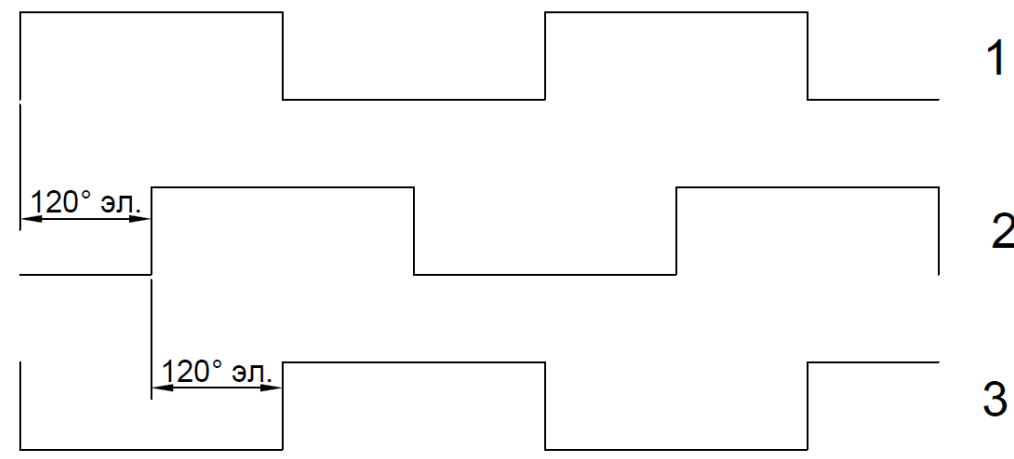

Рис. 3. Меандровая обмотка $\left(q=1, W_{c}=0,5\right)$

Fig. 3. Meander winging $\left(q=1, W_{c}=0,5\right)$.

В этом случае каждая фаза будет представлять собой один непрерывный меандр, выполненный кабелем (шиной), что позволит устранить необходимость соединения секции в фазе и уменьшить потери в лобовых частях, так будет устранена одна лобовая часть в сравнение с витком.

В этом случае расчёт электродвижущей силы фазы может быть выполнен по формуле:

$$
E=B_{\delta c p} \cdot l_{a} \cdot v,(\mathrm{M}),
$$

где $B_{\delta c p}-$ индукция в рабочем зазоре; $l_{a}$ - суммарная активная длина проводников в фазе (без лобовых частей); $v$ - линейная скорость вращения ротора.

Выводы. 1. Проведено сравнение основных параметров синхронный генератор модульной конструкции с возбуждением от постоянных магнитов при разных скоростях ветрового потока.

2. Проведено сравнение асинхронных генераторов с мультипликаторами и синхронных безредукторных генераторов с постоянными магнитами (безкорпусных) по массогабаритным показателям при равных мощностях.

3 пределено оптимальное по электромаг- нитным параметрам соотношение диаметра корпуса к диаметру ротора в заданных габаритах в генераторах модульной конструкции.

4. Определено оптимальное соотношение ширины паза и зубца, при котором обеспечивается максимальный электромагнитный момент генератора в заданных габаритах.

5. Расчётным путём установлены допустимые по нагреву удельные потери с внешней поверхности генераторов модульной конструкции мощностью от 50 до 2000 кВт.

6. Оценка возможности применения «меандровой» обмотки в синхронных генераторах повышенный мощности.

1. Кудря С.О. та інш. Атлас енергетичного потенціалу відновлюваних джерел енергії України. Інститут відновлюваної енергетики НАН України. К. ВіолПринт. 2008. 55 с.

2. Кудря С.О., Перминов Ю.М., Коханевич В.П. Патент на винахід № 106673. Україна. МПК Н02К 16/00. Н02К 21/22. Вітроелектрична установка модульної конструкції. № a2013 01473. заял. 07.02.13. опубл. 25.09.14. Бюл. №9.

3. Костенко М.П., Пиотровский Л.М. Электрические машины. Часть 2. М. Л. издательство «Энергия». 1965. C. $43-55$.

4. Перминов Ю.Н., Конахевич В.П., Шихайлов Н.А., Перминова С.Ю. Определение параметров и основных размеров генераторов для приливных электростанций малой 
мощности (до 1000 кВт). Відновлювальна енергетика. 2017. № 3(50). C. 66-72.

5. Кудря С.А., Перминов Ю.Н., Буденный В.Ф. О методах расчета магнитных систем с постоянными магнитами. Відновлювальна енергетика. 2009. № 4(19) С. 40-43.

6. Балагуров В.А., Галтеев Ф.Ф., Ларионов А.Н. Электрические машины с постоянными магнитами. М. Энергия. 1964. $208 \mathrm{c}$

7. Арнольд Р.P. Расчет и проектирование магнитных систем с постоянными магнитами. М. Энергия. 1969. 260 с.

8. Буль Б.К. Основы теории и расчета магнитных цепей. М. Энергия. 1964. 154 с.

9. Перминов Ю.Н., Монахов Е.А. Сравнение вариантов конструкций синхронных генераторов с возбуждением от постоянных магнитов для ветроустановок. Відновлювана енергетика. 2019. № 2(57). С. 54-60.

\section{REFERENCES}

1. Kudrya $S$. Atlas energetichnogo potencialy vidnovluvanikh dzherel energii Ukraini. [Atlas of energy potential of renewable energy sources in Ukraine]. Institute of Renewable Energy NAS of Ukraine. K. VioletPrint. 2008. 55 p. [in Ukrainian].

2. Kudrya S.O., Perminov Yu.M., Kokhanevich V.P. Patent na vynakhid № 106673. Ukrayina. MPK H02K 16/00. H02K 21/22. Vitroelektrychna ustanovka modulnoyi konstruktsiyi. № a2013 01473. [Patent for invention No. 106673. Ukraine. IPC H02K 16/00. H02K 21/22. Windmill installation of modular structure. A2013 01473]. stated. 07.02.13. published 25.09.14 Bul. № 9. [in Ukrainian].

3. Kostenko M.P., Piotrovskiy L.M. Elekticheskie mashini. Chast 2. [Electrical machines. Part 2]. Moscow. Russia. Energiya. Pp. 43-55. [in Russian].

4. Perminov Yu., Konahevich V., Shihaylov N., Perminova $S$. Opredelenie parametrov i osnovnyih razmerov generatorov dlya prilivnyih elektrostantsiy maloy moschnosti (do $1000 \mathrm{kVt}$ ) [Determination of parameters and basic dimensions of the generator of low power tidal plants (up to $1000 \mathrm{~kW}$ )]. Vidnovluvana energetika. 2017. No. 3(50). Pp. 66-72. [in Russian].

5. Kudrya S., Perminov Yu., Budyonnyi V. O metodakh rascheta magnitnikh system $\mathrm{s}$ postoyanimi magnitami. [About calculation mathods of the magnetic systems with permanent magnets]. Vidnovluvana energetika. 2009. No. 4(19). Pp. 40-43 [in Russian].

6. Balagurov V., Galteev F., Larionov A. Elekticheskie mashini s postoyanimi magnitami. [Permanent magnet machines]. Moscow. Russia. Energiya. 1964. 208 p. [in Russian].

7. Arnold $R$. Rashet i proektirovanie magnitnikh system $\mathrm{s}$ postoyanimi magnitami. [Calculation and design the magnetic systems with permanent magnets]. Moscow. Russia. Energiya. 1969. 260 p. [in Russian].

8. Bul B. Osnovi teorii i rascheta magnitnikh cepej. [Basics of theory and calculation of magnetic circuits]. Moscow. Russia. Energiya. 1964. 154 p. [in Russian].

9. Perminov Yu., Monakhov Y.S. Sravnenie variantov konstrukciy sinkhronnikh generator s vozbuzhdeniev ot postoyanikh magnitov dlya vetroustanovok. [Design comparison of synchronous permanent magnet generator for windturbines]. Vidnovluvana energetika. 2019. No. 2(57). Pp. 54-60. [in Russian].

\section{ПРОЕКТУВАННЯ ВІТРОГЕНЕРАТОРІВ ПІДВЩИННОЇ ПОТУЖНОСТІ (600 $\div 3600)$ КВТ 3І ЗБУДЖЕННЯМ ВІД ПОСТІЙНИХ МАГНІТІВ}

\section{Ю.Н. Перминов ${ }^{1}$, канд.техн.наук, С.А. Монахов ${ }^{2}$,} Л.П. Волков ${ }^{3}$

${ }^{1}$ Інститут відновлюваної енергетики НАН України, 02094, вул. Гната Хоткевича, 20А, м. Киев, Україна.

${ }^{2}$ Національний технічний університет України «Київський політехнічний інститут імені Ігоря Сікорського», 03056, пр. Перемоги, 37, м. Київ, Україна.

${ }^{3}$ Інститут екологічного управління та збалансованого природовикористування,

02002, вул. Нікольсько-Слобідська, 6-Д, м. Київ, Україна.

У статті на основі оцінки характеристик деяких вітрозон Украйни [1] $i$ застосованої при проектуванні швидкості вітру за кордоном проведено порівняння основних параметрів вітрогенераторів. Для иього за певним алгоритмом [4-9] був розрахований ряд синхронних генераторів потужністю від 600 до 3600 кBт з орієнтиром на потужсності машин, шо випускаються «Заводом великих електричних машин» (м. Каховка), але за базову конструкиію при розрахунках прийнятий генератор, представлений в [2]. Особливістю конструкиії иього генератора - відсутність ярма статора (корпусу). Корпусом генератора є пакет статора з обмоткою, тому він являе собою модуль головки вітроустановки, ие дозволяє зменшити його масу $і$ габарити.

До теперішнього часу найбільш широко застосували асинхронні генератори з мультиплікаторами для підвищення частоти обертання, враховуючи, що частота обертання вітроколеса зменшується з підвищенням потужності вітроустановки і становить всього кілька обертів в хвилину. Зі збільшенням частоти обертання зменшується електромагнітний момент, об'єм і маса генератора, але збільшуються відповідні параметри мультиплікатора. В останні роки намітилася тенденція застосування безредукторних синхронних генераторів зі збудженням від постійних магнітів, щзо дозволяє спростити конструкиію агрегату, підвищити надійність установки, виключити необхідність обслуговування редуктора (мультиплікатора) і втрати на збудження. У зв'язку з циим, в роботі проведено порівняння зазначених варіантів виконання агрегатної частини вітроустановок по електромагнітним параметрам, масою і габаритами.

Зміна геометричних співвідномень генератора визначає його електромагнітні параметри, тому відмічені оптимальні відношення діаметрів корпусу $i$ ротора, ширини паза $i$ зубия, визначена залежність геометрії зубцеву зони $i$ потужності від прийнятого числа пазів на полюс і фазу (q); обтрунтована можливість застосування «меандрової》 обмотки в зв'язку з малим розрахунковим значенням числа витків в секиії. Така обмотка дозволяє спростити технологію ї̈ виготовлення, можливість збільшення коефіцієнта заповнення паза і потужності при вирішенні технологічних питань виготовлення. Бібл. 9, рис. 3.

Ключові слова: синхронні генератори, асинхронні генератори, потужність вітроустановки, частота обертів, електромагнітний момент, постійні магніти, число пазів на полюс і фазу, коефіиієнт заповнення паза. 